Volume: 14 Issue: 2 Year: 2017

\title{
Pragmatic awareness of ELT teacher trainees: A study of refusals of requests
}

\author{
Sinem Hergüner ${ }^{1}$ \\ Abdulvahit Çakır ${ }^{2}$
}

\begin{abstract}
This study specifically aims to determine Turkish English Language Teaching (henceforth ELT) teacher trainees' choices in using speech acts set of refusals in terms of directness from the aspect of pragma-linguistics in a Turkish, an English as a Foreign Language (henceforth EFL), context. The randomly chosen participants were 133 ELT teacher trainees (100 female, 33 Male), who are fourth-year students from ELT Departments of Education Faculties at four different universities (Gazi University (GU), Başkent University (BU), Middle East Technical University (METU), Hacettepe University (HU). The study used a questionnaire in the form of Discourse Completion Task (henceforth DCT) based on the Cross-cultural Speech Act Realization Project (CCSARP) (Blum-Kulka and Olshtain 1984) for data collection. The study elicited judgments of various refusal formulations of the trainees in eighteen different situations in terms of directness and indirectness. The context of each situation based on three variables with different levels. These are gender (same-opposite), social status (low-equal-high), and social distance (intimateacquaintance-stranger). Each of the eighteen situations has a different triplet of these variables. The findings are interpreted statistically and verbally. The refusal strategies gathered by this study were analyzed based on a sequence of semantic formulae provided by Beebe and Takahashi (1990). The findings of this study indicate that aspects of refusals may cause difficulties for ELT teacher trainees. The trainees of all the universities employed more statements of excuse/reason/explanation than of other strategies. This is further proof of the value of face. In the whole data what is obviously seen is that teacher trainees mostly prefer indirect strategies. The findings proved that the trainees were sensitive to the status of the requester, and they are less sensitive towards acquaintances. All trainees used most statements of indirect Excuse/reason/explanation when they refused people of each gender. Nevertheless, oppositegender refusals require more elaboration and more care, which proves the trainees' more attention to the requesters of opposite gender. This study suggests the need to raise their pragmatic awareness of Turkish ELT teacher trainees regarding the use of refusal strategies in particular contexts.
\end{abstract}

Keywords: Speech acts; ELT teacher trainees; pragmatic awareness; refusals; requests; directness/indirectness; social status; social distance; gender; discourse completion task (DCT).

\section{Introduction}

Teaching a foreign language specifically in an EFL setting surely requires more than a conscious focus on the grammatical aspects of language, which can be defined as learning about language. However, it is a mere fact that achieving a communication can only be attained when the attention of the learners is directed to social and pragmatic use of the language, which can be defined as learning language. To this end, teaching speech acts may be a great supporter in a

1Ph.D., Gazi University, School of Foreign Languages, herguner0634@gmail.com

2Prof. Dr., Gazi University, Faculty of Education, Department of English Language Teaching, acakir@gazi.edu.tr 
process through which learners are led to develop their pragmatic competence. As one of the aspects of speech acts, refusal strategies are to be taught to EFL students for various reasons. No doubt that teaching refusal strategies, specifically 'refusals of requests', will provide EFL students with the golden opportunity of being and becoming as appropriate as possible in authentic communication contexts. In this respect, measuring the refusal strategies employed by the teacher trainees gain great importance on the grounds that they will be the representatives and most alive resources of the language for the language learners in the future.

Therefore, it is widely accepted that EFL learners should be directed to the pragmatic aspects of the language throughout their learning experience. The actors and actresses of the target language, the EFL teachers, are surely the most important sources of both language and the effective ways and means of learning it. Hence, most of the burden still remains on the shoulders of the pre-service education. Pre-service education is considered to be the most important step in a teacher's professional life, in which most of the beliefs, strategies, dispositions and skills of teaching a foreign language is acquired. This fact leads us to the problem that the knowledge and language competencies of the teacher trainees on pragmatic competence, specifically refusals of request, identified as the research variable of this study, should first be measured so as to decide on a possible remedy in the further research studies.

The speech act of refusal has not been of interest to researchers sufficiently as much as other speech acts such as requests, apologies. Nevertheless, a few studies on refusal strategies (Bebee, Takahashi and Uliss-Weltz, 1990; Chen, 1995; Murphy and Neu, 1996; Olshtain and Weinbach, 1993) have appeared in the literature. However, the speech act of refusing of requests has not been searched and investigated in terms of directness and indirectness of Turkish teacher trainees of English. Second, although there have been a number studies conducted on the speech act refusals in different countries, there are fewer studies (Bulut, 2000; Demir, 2003; Tekyldiz, 2006; Çapar, 2014; Çiftçi, 2016; Ekmekçi, 2015; Han \& Burgucu-Tazegül, 2016) carried out in the Turkish context. Therefore, it is necessary to conduct similar studies on refusal strategies used by Turkish teacher trainees of English in order to contribute to the literature.

As Çakır (2006:154) pointed that "communicating internationally inevitably involves communicating interculturally as well, which probably leads us to encounter factors of cultural differences". He also adds that such kind of differences exist in every language such as the place of silence, tone of voice, appropriate topic of conversation, and expressions as speech act functions (e.g. apologies, suggestions, complaints, refusals, etc.) .

To teach a language we should raise students' pragmatic awareness by drawing their attention to the use of the language rather than only dealing with grammar structures. The situations in which misunderstandings occur due to lack of communicative competence are supposed to be weird and annoying rather than grammatical ones (Akınc1-Akkurt, 2007).

Moreover, according to Alptekin (2002), EFL educators need to consider the implications of the international status of English in terms of appropriate pedagogies and instructional materials that can help learners become successful bilingual and intercultural individuals who are able to function well in both local and international settings. Thus, it is essential to create a communicative atmosphere and prepare a proper classroom setting to achieve a native-like competence in target language.

\section{Purpose}

The goal of the present study is to find out the level of pragmatic awareness of English Language Teaching teacher trainees in terms of directness and indirectness by implementing a DCT to investigate three variables which the literature has identified in other intra-cultural and intercultural communication acts - social status, social distance and gender. 
This study specifically aims to assess 'Turkish ELT teacher trainees' competency in using speech acts set of refusals in terms of directness from the aspect of pragma-linguistics in a Turkish context. To achieve this main goal, this study is supposed to answer the following questions:

1. Do strategies of refusals of requests employed by teacher trainees reflect social status difference?

2. Do strategies of refusals of requests employed by teacher trainees reflect social distance difference?

3. Do strategies of refusals of requests employed by teacher trainees' gender difference?

4. Does social status display divergence in terms of directness?

5. Does social distance display divergence in terms of directness?

6. Does gender display divergence in terms of directness?

\section{Method and Material}

\subsection{The place and time of the study}

Data was collected from 133 ELT teacher trainees studying at four universities namely Başkent University, Gazi university, Hacettepe University and Middle East Technical University in 2007-2008 academic year.

\subsection{Population and sample selection}

In this study, the subjects are 133 ELT teacher trainees (100 female, 33 Male), who are fourth-year students at ELT departments of the faculties of Education in four different universities (Gazi University, Başkent University, METU, Hacettepe University). The randomly chosen participants were observed to be representative of teacher trainees in Turkey in terms of the variables such as socioeconomic demography and language learning history and competencies.

\subsection{Type of study}

This is a descriptive type of study which reveals the present situation as much as the data collection tools are efficient and the data collection process lets.

\subsection{The variables}

There were three main variables of this study. The DCT used in the study covered them in each situation of refuse of requests. The study concentrated on social status, social distance, and gender as the three focal variables. Other potentially relevant factors, such as the time spent to learn English, or the degree of imposition of the requests, were specifically not investigated and left for later research.

\subsection{Data collection}

\subsubsection{Data collection method}

The study used a questionnaire in the form of Discourse Completion Task (DCT) based on the Cross-cultural Speech Act Realization Project (CCSARP) (Blum-Kulka and Olshtain 1984) for data collection. This has been widely used in pragmatic research: Ikoma and Shimura (1994) in refusals; Blum-Kulka and Olshtain (1986) for requests; Banerjee and Carrel (1988) for suggestions. Many findings have been proposed, and significant generalizations have been made on the basis of the data from the DCT. The value of such data is generally recognized, particularly for the purpose of developing "an initial classification of semantic formulae and strategies that will occur in natural speech" (Beebe \& Takahashi: 1989, p.10). A DCT using written questionnaires is appropriate for the purpose of this study because it has some 
specific advantages. Wolfson, Marmor and Jones (1989) describe the use of the DCT as an effective means of gathering a large number of data in a relatively short period. A large number of participants can be surveyed with the DCT more easily than role plays, thus making statistical analysis more feasible. Within the time constraints of the present study, this methodology worked well. The methodology used in this research is mainly based on the methodology used by Beckers (1999). This is a well-designed, well-structured means of eliciting the most data with the least time available. Due to the methodology of written data elicitation, other factors such as prosody (intonation, tone, stress), non-verbal gestures and facial expressions were not observed. There is also a limitation in the fact that written data do not have time constraints: participants can correct their answers. As a result, the answers may differ from what participants really say in real-life situations. However, since collecting learner data naturally is hardly possible as foreign language learners seldom have the opportunity to participate in a real target environment (Trosborg, 1995). Thus, naturalistic data collection, from role-plays or recordings made in natural settings, would be desirable as both a complement and as a self-standing methodology in more extensive studies.

\subsubsection{Data collection tool}

The DCT developed by Blum-Kulka and Olshtain (1984) consists of eighteen refusal situations that vary in terms of social status with three levels: low $(\mathrm{L})$, high $(\mathrm{H})$, and equal $(\mathrm{E})$; social distance with three levels: intimate $(\mathrm{I})$, acquaintance $(\mathrm{A})$, and stranger (S); and gender relationship with two levels: same (S) and opposite (O). All of the questions in the questionnaires are coded, based on the combination of the three variables: social status, social distance, and gender. Thus, each situation needs to make the comparison at least three times with the combinations of the other variables to elicit the necessary data. For instance, the first situation for a female is "You are a mother of two children. One day you are going shopping with your little daughter. She asks if you can buy an expensive doll for her, "Mum, I love that doll so much. Could you please buy it for me?". You refuse her request by saying:....". In this situation, the participant is supposed to refuse a person of Lower (L) social status, Intimate (I) to the participant, and of the Same (S) gender. Participants were presented with the 18 situations in which they were requested to perform some actions. Their task was to refuse in all those situations, and write down what they would say in each situation.

\subsubsection{Data collection time}

The participants voluntarily took part in the survey, which took them about 30 minutes to complete.

\subsection{Limitations of the study}

Stress, intonation and body language are crucial factors in discourse. For further studies, it would be better to use a role play to assess these aspects of real discourse situations.

\subsection{The generalizability of the study}

The findings of the study can easily be generalized to Turkish ELT teacher trainees in that the participants were from the capital city universities covering both state and private universities which can be treated as real samples of the whole country thanks to their geographical place and socio-cultural and demographical situation. 


\subsection{Research ethics}

The necessary permissions were taken from the related units of the above-mentioned universities. Also, the participants were provided with all the information related to the study before they joined the survey. They were able to withdraw at any stage of the study without penalty.

\subsection{Evaluation of data}

As Cohen (1996:21) notes, "one of the concerns of speech act researcher is to arrive at a set of strategies 'typically used by native speakers of the target language". A strategy is a verbal move, such as a statement of regret or a reason which is used as a part of the total act of refusing. In order to arrive at a set of strategies, first, the utterances were divided into idea units. Often but not always the idea unit was an independent clause.

The refusal strategies gathered by this study were analyzed based on a sequence of semantic formulae provided by Beebe, Takahashi and Uliss-Weltz (1990). For example, if a respondent refuses a request for buying a robot for a son by saying "I'm sorry, dear. I don't have enough money. We'll buy it later when you are a bit older". This will be analysed as [regret] + [excuse] + [alternative]. In the process of coding, some of the semantic formulae in Beebe, Takahashi and Uliss-Weltz (1990) were not found in the data, and were therefore removed from the list of semantic formulae. There were also some semantic formulae which we have added, as they appeared in the data many times.

I. Direct:

Classification of Refusals by Beebe, Takahashi and Uliss-Weltz (1990:72-73)

A. Performative

B. Non-performative statement

1."No"

2.Negative willingness ability

II. Indirect

A. Statement of regret

B. Wish

C. Excuse/reason/explanation

D. Statement of alternative

1.I can do $\mathrm{X}$ instead of $\mathrm{Y}$

2. Why don't you do $\mathrm{X}$ instead of $\mathrm{Y}$

E. Set condition for future or past acceptance

F. Promise of future acceptance

G. Statement of principle

H. Statement of philosophy

I. Attempt to dissuade interlocutor

1.Threat/statement of negative consequences to the requester

2.Guilt trip

3.Criticize the request/requester, etc.

4.Request for help, empathy, and assistance by dropping or holding the request.

5.Let interlocutor off the hook

6.Self-defence

$\mathrm{J}$. Acceptance that functions as a refusal

1.Unspecific or indefinite reply

2.Lack of enthusiasm

K. Avoidance

1.Nonverbal 
2.Verbal

a. Topic switch

b. Joke

c. Repetition of part of request, etc.

d. Postponement

e. Hedging

f. Ellipsis

g. Hint

Adjuncts to Refusals

1. Statement of positive opinion/feeling or agreement

2. Statement of empathy

3. Gratitude/appreciation

In this study, one more strategy, Rhetorical Question, which often occurred in the data and pointed in Nguyen's (2006) study as well, was added as the $31^{\text {st }}$ strategy to the Semantic Formula to analyze the data.

\section{Results}

4.1. Results regarding the first research question 'Do strategies of refusals of requests employed by teacher trainees reflect social status difference?'

Table 1. Universities by social status (by interlocutors)

\begin{tabular}{|c|c|c|c|c|c|c|c|c|c|c|c|c|}
\hline & \multicolumn{4}{|c|}{ LOW } & \multicolumn{4}{|c|}{ HIGH } & \multicolumn{4}{|c|}{ EQUAL } \\
\hline & 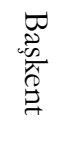 & D. & 崇 & 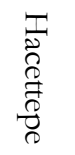 & 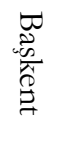 & $\begin{array}{l}\text { D. } \\
\mathbb{N} .\end{array}$ & 尝 & 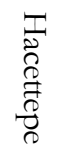 & 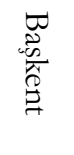 & $\begin{array}{l}\stackrel{2}{\mathbb{N}} \text {. } \\
\text {. }\end{array}$ & 荘 & 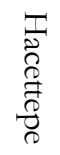 \\
\hline IS & 91 & 121 & 87 & 50 & 73 & 101 & 68 & 33 & 93 & 107 & 74 & 44 \\
\hline SS & 89 & 113 & 79 & 52 & 87 & 116 & 81 & 48 & 74 & 88 & 62 & 37 \\
\hline $\mathrm{AO}$ & 76 & 87 & 68 & 44 & 88 & 104 & 79 & 45 & 78 & 99 & 70 & 42 \\
\hline $\mathrm{IO}$ & 85 & 114 & 74 & 46 & 77 & 120 & 75 & 48 & 75 & 91 & 63 & 45 \\
\hline SO & 76 & 108 & 68 & 44 & 86 & 107 & 82 & 56 & 88 & 102 & 69 & 43 \\
\hline AS & 76 & 94 & 58 & 34 & 67 & 107 & 71 & 44 & 88 & 96 & 68 & 42 \\
\hline Total & 493 & 637 & 434 & 270 & 478 & 655 & 456 & 274 & 496 & 583 & 406 & 253 \\
\hline
\end{tabular}

IS: Intimate Same gender

SS: Stranger Same gender

AO: Acquaintance Opposite gender
IO: Intimate Opposite gender

SO: Stranger Opposite gender

AS: Acquaintance Same gender

Table 1 shows the number of SARs used by all trainees of each university by social status. Overall, trainees of four universities utilized similar numbers of SARs in their refusals. Only the trainees of Başkent University used more strategies to equal status whereas the other trainees of the other three universities utilized the most SARs to high status.

The groups that show different patterns of SARs are used with intimates of the same gender of low status; the situation is the same for intimates of the same gender of equal status. The third group of people that received different numbers of responses from the trainees is intimates of the opposite gender of high status. 
Hergüner, S., \& Çakır, A., (2017). Determining the level of pragmatic awareness of ELT teacher trainees: A study of refusals ofrequests.Journal of Human Sciences, 14(2), 1517-1533. doi:10.14687/jhs.v14i2.4575

Overall, trainees of Başkent University utilized nearly the same number of SARs across the three levels of social status. The situation is the same for Hacettepe University across the three levels of social status. Therefore, trainees of Başkent University and Hacettepe University do not have clear preferences by social status. Trainees of Gazi University, on the other hand, varied the total number of semantic formulae when they refused different people from different social status, with distinctive behaviors to people of equal status. It is the same for trainees of METU. They also made a difference the total number of semantic formulae when they refused different people from different social status, again with distinctive behaviors to people of equal status.

\subsection{Results regarding the second research question 'Do strategies of refusals of requests employed by teacher trainees reflect social distance difference?'.}

Table 2. Universities by social distance (by interlocutors)

\begin{tabular}{|c|c|c|c|c|c|c|c|c|c|c|c|c|}
\hline & \multicolumn{4}{|c|}{ INTIMATE } & \multicolumn{4}{|c|}{ ACQUAINTANCE } & \multicolumn{4}{|c|}{ STRANGER } \\
\hline & 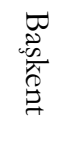 & $\begin{array}{l}\text { बे. } \\
\text { N. }\end{array}$ & 峴 & 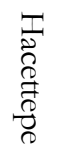 & 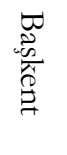 & $\begin{array}{l}\text { D. } \\
\mathbb{N}\end{array}$ & 想 & 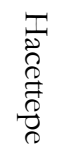 & 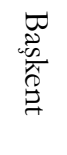 & $\begin{array}{l}\stackrel{\vec{D}}{\mathbb{N}} . \\
\text {. }\end{array}$ & 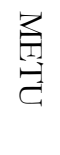 & $\begin{array}{l}\mathbb{T} \\
\stackrel{0}{0} \\
\stackrel{0}{*} \\
\stackrel{0}{0}\end{array}$ \\
\hline LS & 91 & 121 & 87 & 50 & 76 & 94 & 58 & 34 & 89 & 113 & 79 & 52 \\
\hline LO & 85 & 114 & 74 & 46 & 76 & 87 & 68 & 44 & 76 & 108 & 68 & 44 \\
\hline $\mathrm{HO}$ & 77 & 120 & 75 & 48 & 88 & 104 & 79 & 45 & 86 & 107 & 82 & 56 \\
\hline $\mathrm{EO}$ & 75 & 91 & 63 & 45 & 78 & 99 & 70 & 42 & 88 & 102 & 69 & 43 \\
\hline ES & 93 & 107 & 74 & 44 & 88 & 96 & 68 & 42 & 74 & 88 & 62 & 37 \\
\hline HS & 73 & 101 & 68 & 33 & 67 & 107 & 71 & 44 & 87 & 116 & 81 & 48 \\
\hline Total & 494 & 654 & 441 & 266 & 473 & 587 & 414 & 251 & 500 & 634 & 441 & 280 \\
\hline
\end{tabular}

LS: Low social status Same gender LO: Low social status Opposite gender HO: High social status Opposite gender
EO: Equal social status Opposite gender ES: Equal social status Same gender HS: High social status Same gender

Table 2 describes the number of SARs in terms of social distance for the trainees of four universities (Başkent University, Gazi University, Middle East Technical University, Hacettepe University). Overall, trainees of four universities utilized similar numbers of SARs in their refusals. The trainees used fewer strategies to acquaintances than intimates and strangers.

The trainees employed the most SARs for the people of low status and of the same gender acquaintances. Overall, trainees of Başkent University utilized nearly the same number of SARs across the three levels of social distance the situation is the same for Hacettepe University across the three levels of social distance. Therefore, the trainees of Basskent University and Hacettepe University do not have clear preferences by social status. Trainees of Gazi University, on the other hand, varied the total number of semantic formulae when they refused different people from different social distance, with distinctive behaviors to people of equal status. It is the same for trainees of METU. They also made a difference in the total number of semantic formulae when they refused different people from different social status, again with distinctive behaviors to people of equal status.

Overall, the trainees of Başkent University and METU used nearly the same number of SARs when they communicated with the three groups: intimates, acquaintances, and strangers. On 
Hergüner, S., \& Çakır, A., (2017). Determining the level of pragmatic awareness of ELT teacher trainees: A study of refusals ofrequests.Journal of Human Sciences, 14(2), 1517-1533. doi:10.14687/jhs.v14i2.4575

the other hand, the trainees of Gazi University employed a higher number of SARs when they refused intimates. All in all, the number of the SARs employed by the trainees of Gazi University is much higher than the other trainees of the three universities.

\subsection{Results regarding the third research question 'Do strategies of refusals of requests employed by teacher trainees' gender difference?'}

Table 3. Universities by gender (by interlocutors)

\begin{tabular}{|l|c|c|c|c|c|c|c|c|}
\hline & \multicolumn{4}{|c|}{ SAME } & \multicolumn{4}{c|}{ OPPOSITE } \\
\hline & Başkent & Gazi & METU & Hacettepe & Başkent & Gazi & METU & Hacettepe \\
\hline LI & 91 & 121 & 87 & 50 & 85 & 114 & 74 & 46 \\
\hline LS & 89 & 113 & 79 & 52 & 76 & 108 & 68 & 44 \\
\hline LA & 76 & 94 & 58 & 34 & 76 & 87 & 68 & 44 \\
\hline HA & 67 & 107 & 71 & 44 & 88 & 104 & 79 & 45 \\
\hline ES & 74 & 88 & 62 & 37 & 88 & 102 & 69 & 43 \\
\hline EA & 88 & 96 & 68 & 42 & 78 & 99 & 70 & 42 \\
\hline HS & 87 & 116 & 81 & 48 & 86 & 107 & 82 & 56 \\
\hline EI & 93 & 107 & 74 & 44 & 75 & 91 & 63 & 45 \\
\hline HI & 73 & 101 & 68 & 33 & 77 & 120 & 75 & 48 \\
\hline Total & 738 & 943 & 648 & 384 & 729 & 932 & 648 & 413 \\
\hline
\end{tabular}

LI: Low social status Intimate

LS: Low social status Stranger LA: Low social status Acquaintance

HA: High social status Acquaintance
ES: Equal social status Stranger

EA: Equal social status Acquaintance

HS: High social status Stranger

EI: Equal social status Intimate

HI: High social status Intimate

Table 3 describes the number of SARs in terms of the gender for the trainees of four universities. Overall, trainees of four universities utilized similar numbers of SARs in their refusals for different genders. The trainees used fewer strategies to the people of the same gender than those of opposite gender.

The trainees employed the most SARs for intimates of low status of the same gender. Overall, trainees of METU utilized the same number of SARs across the two levels of gender. While the trainees of Gazi and Başkent utilized more SARs for the people of the same gender, Hacettepe utilized fewer SARs. Therefore, trainees of METU do not have clear preferences by social status. On the other hand trainees of other universities, especially Gazi University, more or less varied the total number of semantic formulae when they refused different people from different gender groups.

As it can be observed in Table 3, the trainees used the most SARs for the same gender on the level of intimates of low status. For the people of opposite gender strangers of high status required the most SARs. 
Hergüner, S., \& Çakır, A., (2017). Determining the level of pragmatic awareness of ELT teacher trainees: A study of refusals ofrequests.Journal of Human Sciences, 14(2), 1517-1533. doi:10.14687/jhs.v14i2.4575

\subsection{Results regarding the fourth research question 'Does social status display divergence in terms of directness?'}

Table 4. Universities by social distance (bySARs)

\begin{tabular}{|c|c|c|c|c|c|c|c|c|c|c|c|c|c|}
\hline \multirow[b]{2}{*}{ SARs } & \multicolumn{5}{|c|}{ INTIMATE } & \multicolumn{4}{|c|}{ ACQUAINTANCE } & \multicolumn{4}{|c|}{ STRANGER } \\
\hline & $\stackrel{8}{\varnothing}$ & 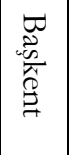 & Q & 尩 & 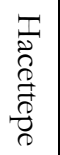 & 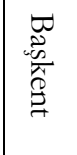 & Q & 宸 & 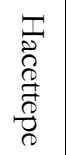 & 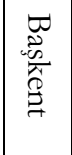 & Q & 空 & 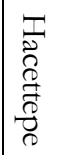 \\
\hline Direct Performative & 1 & 1 & 0 & 0 & 0 & 0 & 1 & 0 & 0 & 0 & 1 & 0 & 0 \\
\hline Direct Non-performative "No" & 2 & 24 & 24 & 17 & 8 & 18 & 30 & 12 & 15 & 21 & 40 & 17 & 13 \\
\hline $\begin{array}{l}\text { Direct Non-performative Negative willingness } \\
\text { ability }\end{array}$ & 3 & 59 & 56 & 49 & 24 & 78 & 73 & 66 & 28 & 95 & 114 & 77 & 44 \\
\hline Indirect Statement of regret & 4 & 85 & 92 & 68 & 37 & 105 & 127 & 99 & 54 & 104 & 127 & 98 & 66 \\
\hline Indirect Statement of Wish & 5 & 1 & 16 & 1 & 4 & 1 & 8 & 1 & 3 & 2 & 1 & 0 & 1 \\
\hline Indirect Excuse/reason/explanation & 6 & 148 & 215 & 118 & 83 & 168 & 207 & 140 & 80 & 70 & 99 & 63 & 40 \\
\hline $\begin{array}{l}\text { Indirect Statement of alternative: I can do X instead } \\
\text { of Y }\end{array}$ & 7 & 9 & 19 & 13 & 16 & 2 & 6 & 7 & 3 & 2 & 6 & 6 & 1 \\
\hline $\begin{array}{l}\text { Indirect Statement of alternative: Why don't you do } \\
\mathrm{X} \text { instead of Y }\end{array}$ & 8 & 13 & 12 & 14 & 4 & 9 & 7 & 7 & 6 & 11 & 20 & 16 & 7 \\
\hline Indirect Set condition for future or past acceptance & 9 & 5 & 6 & 4 & 1 & 1 & 4 & 2 & 3 & 0 & 3 & 0 & 0 \\
\hline Indirect Promise of future acceptance & 10 & 9 & 11 & 10 & 9 & 1 & 0 & 0 & 0 & 1 & 0 & 0 & 0 \\
\hline Indirect Statement of principle & 11 & 0 & 0 & 0 & 1 & 4 & 7 & 4 & 3 & 18 & 8 & 4 & 4 \\
\hline Indirect Statement of philosophy & 12 & 6 & 2 & 3 & 0 & 10 & 10 & 1 & 2 & 73 & 100 & 65 & 34 \\
\hline $\begin{array}{l}\text { Attempt to dissuade interlocutor: } \\
\text { Threat/statement of negative consequences to the } \\
\text { requester }\end{array}$ & 13 & 5 & 6 & 1 & 3 & 9 & 17 & 5 & 12 & 16 & 7 & 3 & 7 \\
\hline Attempt to dissuade interlocutor :Guilt trip & 14 & 0 & 2 & 2 & 0 & 1 & 2 & 12 & 2 & 2 & 2 & 5 & 0 \\
\hline $\begin{array}{l}\text { Attempt to dissuade interlocutor : Criticize the } \\
\text { request/requester, etc. }\end{array}$ & 15 & 13 & 9 & 5 & 5 & 14 & 21 & 8 & 9 & 24 & 30 & 26 & 15 \\
\hline $\begin{array}{l}\text { Attempt to dissuade interlocutor: } \\
\text { Request for help, empathy, and assistance by } \\
\text { dropping or holding the request. }\end{array}$ & 16 & 8 & 5 & 14 & 2 & 7 & 1 & 6 & 3 & 4 & 2 & 5 & 2 \\
\hline $\begin{array}{l}\text { Attempt to dissuade interlocutor :Let interlocutor off } \\
\text { the hook }\end{array}$ & 17 & 3 & 7 & 5 & 2 & 2 & 0 & 1 & 2 & 1 & 0 & 2 & 0 \\
\hline Attempt to dissuade interlocutor :Self defence & 18 & 17 & 14 & 16 & 8 & 1 & 1 & 0 & 0 & 10 & 24 & 15 & 11 \\
\hline $\begin{array}{l}\text { Acceptance that functions as a refusal:Unspecific or } \\
\text { indefinite reply }\end{array}$ & 19 & 0 & 3 & 1 & 0 & 3 & 5 & 5 & 1 & 0 & 2 & 0 & 0 \\
\hline $\begin{array}{l}\text { Acceptance that functions as a refusal:Lack of } \\
\text { enthusiasm }\end{array}$ & 20 & 0 & 1 & 1 & 1 & 2 & 6 & 2 & 1 & 1 & 1 & 0 & 0 \\
\hline Avoidance/ Verbal: Topic switch & 21 & 0 & 0 & 0 & 0 & 0 & 0 & 0 & 0 & 0 & 0 & 0 & 0 \\
\hline Avoidance/ Verbal: Joke & 22 & 5 & 1 & 2 & 0 & 3 & 2 & 3 & 0 & 2 & 1 & 0 & 1 \\
\hline $\begin{array}{l}\text { Avoidance/ Verbal: Repetition of part of request, } \\
\text { etc. }\end{array}$ & 23 & 2 & 1 & 1 & 2 & 6 & 4 & 2 & 1 & 1 & 1 & 0 & 1 \\
\hline Avoidance/ Verbal: Postponement & 24 & 13 & 28 & 23 & 7 & 2 & 2 & 6 & 3 & 4 & 1 & 0 & 0 \\
\hline Avoidance/ Verbal: Hedging & 25 & 50 & 80 & 56 & 40 & 8 & 24 & 18 & 14 & 26 & 28 & 26 & 25 \\
\hline Avoidance/ Verbal: Ellipsis & 26 & 3 & 1 & 0 & 0 & 4 & 2 & 0 & 0 & 2 & 1 & 2 & 3 \\
\hline Avoidance/ Verbal: Hint & 27 & 0 & 0 & 0 & 0 & 0 & 0 & 0 & 0 & 0 & 0 & 0 & 0 \\
\hline $\begin{array}{l}\text { Adjuncts to Refusals: Statement of positive } \\
\text { opinion/feeling or agreement }\end{array}$ & 28 & 10 & 31 & 10 & 7 & 7 & 14 & 6 & 5 & 1 & 1 & 2 & 1 \\
\hline Adjuncts to Refusals: Statement of empathy & 29 & 2 & 6 & 5 & 2 & 1 & 1 & 0 & 0 & 1 & 1 & 3 & 1 \\
\hline Adjuncts to Refusals: Gratitude/appreciation & 30 & 0 & 0 & 0 & 0 & 0 & 0 & 0 & 0 & 0 & 1 & 0 & 0 \\
\hline Rhetorical questions & 31 & 3 & 6 & 2 & 0 & 6 & 5 & 1 & 1 & 8 & 12 & 6 & 3 \\
\hline
\end{tabular}

Table 4 illustrates the number of SARs across social distances among the four groups. A distinguishing feature of the table is the frequency of the word "NO" in refusal sentences across 
Hergüner, S., \& Çakır, A., (2017). Determining the level of pragmatic awareness of ELT teacher trainees: A study of refusals ofrequests.Journal of Human Sciences, 14(2), 1517-1533. doi:10.14687/jhs.v14i2.4575

the three levels of social distance. The trainees of Gazi University employed approximately three times more instances of "NO" than those of Hacettepe University, who preferred the direct performative use of saying "NO"less. Another difference between the four groups of speakers is the use of Indirect Excuse/reason/explanation which the trainees of Gazi University used more than twice those of Hacettepe University, who used less number of Indirect Excuse/reason/explanation statements. Finally, the trainees of Gazi University utilized more than twice as many Indirect Statement of regret term in their refusals in comparison to the trainees of Hacettepe University.

According to Table 4 the followings are the SARs mostly used for intimates: Indirect Excuse/reason/explanation, Indirect Statement of regret and Avoidance/ Verbal: Hedging.

The followings are the mostly preferred SARs for acquaintances: Indirect Excuse/reason/explanation, Indirect Statement of regret and Direct Non-performative Negative willingness ability.

The followings are the mostly utilized SARs for strangers: Indirect Statement of regret, Direct Non-performative Negative willingness ability, Indirect Excuse/reason/explanation and Indirect Statement of philosophy.

\subsection{Results regarding the fifth research question 'Does social status display divergence in terms of directness?'}

Table 5. Universities by social status (bySARs)

\begin{tabular}{|c|c|c|c|c|c|c|c|c|c|c|c|c|c|}
\hline \multirow[b]{2}{*}{ SARs } & \multirow[b]{2}{*}{ 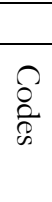 } & \multicolumn{4}{|c|}{ LOW } & \multicolumn{4}{|c|}{ EQUAL } & \multicolumn{4}{|c|}{ HIGH } \\
\hline & & 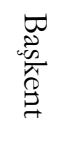 & D. & 当 & 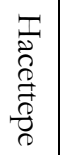 & 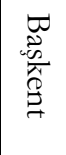 & D. & 当 & 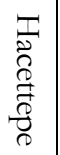 & 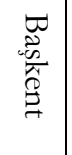 & Q & 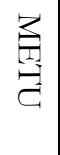 & 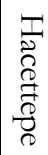 \\
\hline Direct Performative & 1 & 1 & 1 & 0 & 0 & 0 & 1 & 0 & 0 & 0 & 0 & 0 & 0 \\
\hline Direct Non-performative "No" & 2 & 29 & 39 & 26 & 15 & 19 & 22 & 7 & 10 & 15 & 33 & 13 & 11 \\
\hline Direct Non-performative Negative willingness ability & 3 & 94 & 106 & 95 & 49 & 73 & 72 & 45 & 22 & 65 & 65 & 52 & 25 \\
\hline Indirect Statement of regret & 4 & 71 & 85 & 61 & 40 & 128 & 140 & 114 & 66 & 95 & 121 & 90 & 51 \\
\hline Indirect Statement of Wish & 5 & 1 & 4 & 1 & 3 & 2 & 14 & 1 & 3 & 1 & 7 & 0 & 2 \\
\hline Indirect Excuse/reason/explanation & 6 & 112 & 130 & 84 & 50 & 173 & 237 & 154 & 95 & 101 & 154 & 83 & 58 \\
\hline Indirect Statement of alternative: I can do X instead of Y & 7 & 7 & 16 & 10 & 7 & 5 & 8 & 8 & 10 & 1 & 7 & 8 & 3 \\
\hline $\begin{array}{l}\text { Indirect Statement of alternative: Why don't you do X } \\
\text { instead of Y }\end{array}$ & 8 & 11 & 14 & 9 & 5 & 15 & 12 & 16 & 7 & 7 & 13 & 12 & 5 \\
\hline Indirect Set condition for future or past acceptance & 9 & 1 & 4 & 0 & 0 & 5 & 7 & 4 & 2 & 0 & 2 & 2 & 2 \\
\hline Indirect Promise of future acceptance & 10 & 5 & 6 & 3 & 7 & 2 & 0 & 0 & 0 & 4 & 5 & 7 & 2 \\
\hline Indirect Statement of principle & 11 & 9 & 8 & 3 & 6 & 11 & 4 & 4 & 1 & 2 & 3 & 1 & 1 \\
\hline Indirect Statement of philosophy & 12 & 30 & 30 & 15 & 7 & 0 & 1 & 1 & 0 & 59 & 81 & 53 & 29 \\
\hline $\begin{array}{l}\text { Attempt to dissuade interlocutor: } \\
\text { Threat/statement of negative consequences to the } \\
\text { requester }\end{array}$ & 13 & 21 & 19 & 6 & 11 & 1 & 4 & 1 & 6 & 8 & 7 & 2 & 5 \\
\hline Attempt to dissuade interlocutor :Guilt trip & 14 & 1 & 4 & 9 & 0 & 1 & 1 & 8 & 2 & 1 & 1 & 2 & 0 \\
\hline $\begin{array}{l}\text { Attempt to dissuade interlocutor: } \\
\text { request/requester, etc. }\end{array}$ & 15 & 33 & 46 & 28 & 21 & 8 & 11 & 5 & 7 & 10 & 3 & 6 & 1 \\
\hline $\begin{array}{l}\text { Attempt to dissuade interlocutor: } \\
\text { Request for help, empathy, and assistance by dropping } \\
\text { or holding the request. }\end{array}$ & 16 & 3 & 2 & 4 & 2 & 6 & 2 & 5 & 1 & 10 & 4 & 16 & $\overline{4}$ \\
\hline $\begin{array}{l}\text { Attempt to dissuade interlocutor :Let interlocutor off } \\
\text { the hook }\end{array}$ & 17 & 0 & 0 & 2 & 0 & 3 & 0 & 0 & 0 & 3 & 7 & 6 & 4 \\
\hline Attempt to dissuade interlocutor :Self-defence & 18 & 10 & 25 & 15 & 10 & 0 & 0 & 0 & 1 & 18 & 14 & 16 & 8 \\
\hline $\begin{array}{l}\text { Acceptance that functions as a refusal: Unspecific or } \\
\text { indefinite reply }\end{array}$ & 19 & 1 & 6 & 4 & 0 & 1 & 1 & 0 & 0 & 1 & 3 & 2 & 1 \\
\hline
\end{tabular}


Hergüner, S., \& Çakır, A., (2017). Determining the level of pragmatic awareness of ELT teacher trainees: A study of refusals ofrequests.Journal of Human Sciences, 14(2), 1517-1533. doi:10.14687/jhs.v14i2.4575

\begin{tabular}{|l|r|r|r|r|r|r|r|r|r|r|r|r|r|}
\hline $\begin{array}{l}\text { Acceptance that functions as a refusal: Lack of } \\
\text { enthusiasm }\end{array}$ & 20 & 3 & 1 & 0 & 0 & 3 & 0 & 2 & 2 & 2 & 2 & 0 \\
\hline Avoidance/ Verbal: Topic switch & 21 & 0 & 0 & 0 & 0 & 0 & 0 & 0 & 0 & 0 & 0 & 0 & 0 \\
\hline Avoidance/ Verbal: Joke & 22 & 1 & 1 & 2 & 1 & 6 & 1 & 2 & 0 & 3 & 2 & 1 & 0 \\
\hline Avoidance/ Verbal: Repetition of part of request, etc. & 23 & 2 & 3 & 0 & 1 & 1 & 0 & 1 & 1 & 6 & 3 & 2 & 2 \\
\hline Avoidance/ Verbal: Postponement & 24 & 11 & 18 & 21 & 6 & 4 & 2 & 3 & 2 & 4 & 11 & 5 & 2 \\
\hline Avoidance/ Verbal: Hedging & 25 & 24 & 39 & 27 & 25 & 13 & 15 & 11 & 10 & 47 & 78 & 62 & 44 \\
\hline Avoidance/ Verbal: Ellipsis & 26 & 4 & 1 & 1 & 1 & 4 & 2 & 0 & 1 & 1 & 1 & 1 & 1 \\
\hline Avoidance/ Verbal: Hint & 27 & 0 & 0 & 0 & 0 & 0 & 0 & 0 & 0 & 0 & 0 & 0 & 0 \\
\hline $\begin{array}{l}\text { Adjuncts to Refusals: Statement of positive } \\
\text { opinion/feeling or agreement }\end{array}$ & 28 & 2 & 6 & 0 & 1 & 6 & 18 & 9 & 2 & 10 & 22 & 9 & 10 \\
\hline Adjuncts to Refusals: Statement of empathy & 29 & 2 & 6 & 6 & 1 & 2 & 0 & 2 & 2 & 0 & 2 & 0 & 0 \\
\hline Adjuncts to Refusals: Gratitude/appreciation & 30 & 0 & 1 & 0 & 0 & 0 & 0 & 0 & 0 & 0 & 0 & 0 & 0 \\
\hline Rhetorical questions & 31 & 6 & 14 & 1 & 1 & 7 & 5 & 5 & 0 & 4 & 4 & 3 & 3 \\
\hline
\end{tabular}

Table 5 describes the number of SARs across the three levels of social status. For low social status, the mostly preferred three SARs are Indirect Excuse/reason/explanation, Direct Nonperformative Negative willingness ability and Indirect Statement of regret. For equal social status, the mostly used SARs are Indirect Excuse/reason/explanation, Indirect Statement of regret and Direct Non-performative Negative willingness ability. For high social status the mostly used SARs are Indirect Excuse/reason/explanation, Indirect Statement of regret and Avoidance/ Verbal: Hedging.

A comparison between the four groups showed that trainees of Gazi University employed a much larger number of the word "NO" in their refusals than the trainees of other three universities. With regard to Indirect Excuse/reason/explanation, trainees of Gazi University employed nearly three times more statements of this kind than Hacettepe University across the three levels of social status.

\subsection{Results regarding the sixth research question 'Does gender display divergence in terms of directness?'}

Table 6. Universities by gender (bySARs)

\begin{tabular}{|c|c|c|c|c|c|c|c|c|c|}
\hline \multirow[b]{2}{*}{ SARs } & \multirow[b]{2}{*}{$\begin{array}{l}\delta \\
\frac{2}{8} \\
\infty\end{array}$} & \multicolumn{4}{|c|}{ SAME } & \multicolumn{4}{|c|}{ OPPOSITE } \\
\hline & & 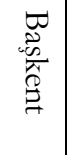 & $\begin{array}{l}\text { Q } \\
\mathbb{N}\end{array}$ & $\underset{\mathrm{C}}{\stackrel{\mathrm{Z}}{\mathrm{Z}}}$ & 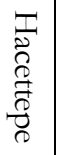 & 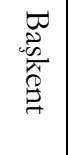 & 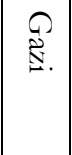 & 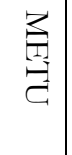 & 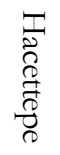 \\
\hline Direct Performative & 1 & 1 & 1 & 0 & 0 & 0 & 1 & 0 & 0 \\
\hline Direct Non-performative "No" & 2 & 39 & 57 & 20 & 25 & 24 & 37 & 26 & 11 \\
\hline Direct Non-performative Negative willingness ability & 3 & 119 & 120 & 100 & 47 & 113 & 123 & 92 & 49 \\
\hline Indirect Statement of regret & 4 & 141 & 153 & 128 & 73 & 153 & 193 & 137 & 84 \\
\hline Indirect Statement of Wish & 5 & 2 & 9 & 1 & 2 & 2 & 16 & 1 & 6 \\
\hline Indirect Excuse/reason/explanation & 6 & 177 & 244 & 152 & 94 & 209 & 277 & 169 & 109 \\
\hline Indirect Statement of alternative: I can do X instead of Y & 7 & 7 & 22 & 18 & 7 & 6 & 9 & 8 & 13 \\
\hline Indirect Statement of alternative: Why don't you do X instead of Y & 8 & 17 & 27 & 23 & 12 & 16 & 12 & 14 & 5 \\
\hline Indirect Set condition for future or past acceptance & 9 & 2 & 6 & 2 & 2 & 4 & 7 & 4 & 2 \\
\hline Indirect Promise of future acceptance & 10 & 6 & 8 & 9 & 5 & 5 & 3 & 1 & 4 \\
\hline Indirect Statement of principle & 11 & 13 & 7 & 4 & 4 & 9 & 8 & 4 & 4 \\
\hline Indirect Statement of philosophy & 12 & 47 & 67 & 36 & 20 & 42 & 45 & 33 & 16 \\
\hline $\begin{array}{l}\text { Attempt to dissuade interlocutor: } \\
\text { Threat/statement of negative consequences to the requester }\end{array}$ & 13 & 15 & 18 & 8 & 11 & 15 & 12 & 1 & 11 \\
\hline Attempt to dissuade interlocutor :Guilt trip & 14 & 3 & 3 & 9 & 1 & 0 & 3 & 10 & 1 \\
\hline Attempt to dissuade interlocutor: Criticize the request/requester, etc. & 15 & 18 & 25 & 13 & 10 & 33 & 35 & 26 & 19 \\
\hline
\end{tabular}


Hergüner, S., \& Çakır, A., (2017). Determining the level of pragmatic awareness of ELT teacher trainees: A study of refusals ofrequests.Journal of Human Sciences, 14(2), 1517-1533. doi:10.14687/jhs.v14i2.4575

\begin{tabular}{|l|r|r|r|r|r|r|r|r|r|}
\hline $\begin{array}{l}\text { Attempt to dissuade interlocutor: } \\
\text { Request for help, empathy, and assistance by dropping or holding the } \\
\text { request. }\end{array}$ & 16 & 1 & 10 & 2 & 10 & 7 & 5 \\
\hline Attempt to dissuade interlocutor :Let interlocutor off the hook & 17 & 2 & 7 & 6 & 2 & 4 & 0 & 2 & 2 \\
\hline Attempt to dissuade interlocutor :Self-defence & 18 & 16 & 14 & 17 & 9 & 12 & 25 & 14 & 10 \\
\hline Acceptance that functions as a refusal: Unspecific or indefinite reply & 19 & 2 & 5 & 3 & 0 & 1 & 5 & 3 & 1 \\
\hline Acceptance that functions as a refusal: Lack of enthusiasm & 20 & 3 & 6 & 1 & 1 & 0 & 2 & 2 & 1 \\
\hline Avoidance/ Verbal: Topic switch & 21 & 0 & 0 & 0 & 0 & 0 & 0 & 0 & 0 \\
\hline Avoidance/ Verbal: Joke & 22 & 4 & 1 & 2 & 1 & 6 & 3 & 3 & 0 \\
\hline Avoidance/ Verbal: Repetition of part of request, etc. & 23 & 3 & 4 & 1 & 1 & 6 & 2 & 2 & 3 \\
\hline Avoidance/ Verbal: Postponement & 24 & 15 & 20 & 11 & 3 & 4 & 11 & 18 & 7 \\
\hline Avoidance/ Verbal: Hedging & 25 & 54 & 83 & 56 & 40 & 30 & 49 & 44 & 39 \\
\hline Avoidance/ Verbal: Ellipsis & 26 & 2 & 2 & 2 & 2 & 7 & 2 & 0 & 1 \\
\hline Avoidance/ Verbal: Hint & 27 & 0 & 0 & 0 & 0 & 0 & 0 & 0 & 0 \\
\hline Adjuncts to Refusals: Statement of positive opinion/feeling or agreement & 28 & 9 & 19 & 9 & 6 & 9 & 27 & 9 & 7 \\
\hline Adjuncts to Refusals: Statement of empathy & 29 & 3 & 6 & 4 & 2 & 1 & 2 & 4 & 1 \\
\hline Adjuncts to Refusals: Gratitude/appreciation & 30 & 0 & 0 & 0 & 0 & 0 & 1 & 0 & 0 \\
\hline Rhetorical questions & 31 & 9 & 8 & 3 & 2 & 8 & 15 & 6 & 2 \\
\hline
\end{tabular}

Table 6 shows that for people of the same gender, the first mostly used strategies are Indirect Excuse/reason/explanation, Indirect Statement of regret and Direct Non-performative Negative willingness ability. The situation is the same for people of opposite gender as well.

\section{Discussion}

\subsection{General discussion}

Several broad tendencies emerge from the analysis of the results. First, the trainees of all the universities employed more statements of excuse/reason/explanation than of other strategies. This is further proof of what has been claimed as the value of face. For Turks, though speaking in English, refusals reflected traditional Turkish culture, in which people tend to be more careful about the way they refuse. In other words, to avoid disappointing their interlocutors they gave a variety of reasons in order to provide a rationale for the refusal.

With regard to the statements of regret, the number of them is in the second rank after excuse/reason/explanation. Therefore, it can be said that the trainees are apt to express refusals with care. They took time to show their regrets when they refused to show that they were unwilling to say "NO". Turks belong to Asian culture, where the value of face-saving acts should be carefully observed. This suggests that Turks felt sorry for what they refused. They definitely did not want their conversation partners to feel humiliated. Some phrases that can be listed under the category of statements of regret are "I'm sorry...", "I'm afraid that..."

Indirect statements of wish are also relevant. The most popular phrases are "I wish I could", and "I wish you could". The trainees of Gazi University also employed the remarkably highest number of "NO" phrases in their responses to requests. This sharp difference shows that the trainees of Gazi University are much more direct than those of other universities. Saying "NO" is a direct non-performative act, only slightly less confronting than the explicit performative "I refuse". Turkey is a highly structured and traditional society. Etiquette and harmony are very important. "Saving face" is a key concept. The Turks are anxious to avoid unpleasantness and confrontation. They try to avoid saying "No." Instead, say, "This could be very difficult," to allow conversation partners to save face. Directly saying "NO" is a serious face-threatening act. The trainees of Gazi University when refusing by directly saying "NO", tend to offer more statements of alternatives than their counterparts. This can be interpreted in terms of Confucianism: that "when communicating, those that follow Confucian philosophy would be concerned with status relationships (Samovar and Porter 2001:p.112). 
In the whole data what is obviously seen is that teacher trainees mostly prefer indirect strategies. However, there are some indirect strategies which were not used by the trainees. They are Avoidance/ Verbal: Topic switch and Avoidance/ Verbal: Hint.

\subsection{Discussion of social status}

Four groups of trainees showed differences in the amount of SARs when they dealt with people of the three social status groups. While trainees of Gazi University, Hacettepe University and Middle East Technical University used the most SARs for people of high status, the trainees of Başkent University employed the most SARs for people of equal status. Besides, all the trainees used mostly Indirect Excuse/reason/explanation statements and mostly to people of equal status. In a nutshell, the trainees were sensitive to the status of the requester.

\subsection{Discussion of social distance}

They employed more SARs for intimates and strangers, while the number is lowerfor acquaintances. This shows they are less sensitive towards acquaintances. Except for the trainees of Gazi University, the trainees employed nearly the same amount of SARs for the three groups of people in terms of social distance, but they employed higher figures for intimates. This might be because Turks are very careful when they refused their intimates. The culture of Turkish places a high value on intimacy between friends and relatives. The desire to achieve harmony between the self and the non-self remains an essential preoccupation of the Turkish culture in interpersonal relations. Thus, the participants tend to use more SARs in their refusals to intimates.

They all used the least statements of excuse/reason/explanation in their refusals to strangers when compared with intimates and acquaintances. In English and Turkish perceptions, strangers are considered to be distanced. So they do not care for them as much as for their intimates and acquaintances that will be in longer-term relationships with them. On the other hand, they used the highest number of direct non-performative negative willingness when they refused strangers. This again shows the less attention shown to strangers.

\subsection{Discussion of gender}

The gender of conversational partners is relevant: all trainees used most statements of indirect Excuse/reason/explanation when they refused people of each gender. Nevertheless, opposite-gender refusals require more elaboration and more care. All trainees used alot of statements of regret when they refused people of the opposite gender. This suggests that they are sensitive to the opposite gender, and so show that many statements of regret to their conversational partners. While METU used very similar numbers of "NO" phrases in their refusals, the rest of the trainees employed more "NO" phrases for the people of the same gender. This illustrates that trainees show more attention to the requesters of opposite gender.

\section{Conclusions and recommendations}

Based on questionnaire data asking what individuals would do, refusals of teacher trainees of four universities (Gazi University, Başkent University, METU and Hacettepe University) are different, though they do share some similarities. The trainees are apt to express refusals with caution and/or care. Thus, the number for 'No' is one of the lowest in the group. In addition, the excuses/reasons/explanations are more related to their readiness to reveal their disinclinations to comply. The trainees of Gazi University are more direct in the ways they refuse: they employed more "NO" phrases than the other trainees. They all show the similar numbers of SARs when they communicate with people of the three social statuses and social distances, but the trainees of Gazi University are more sensitive to the social statuses and social distances of the requesters. 
The gender of conversational partners is relevant: all trainees used most statements of indirect Excuse/reason/explanation when they refused people of each gender. Nevertheless, opposite-gender refusals require more elaboration and more care. Students learning English should be aware that direct refusals are generally acceptable among English and American people. Thus they should not feel hurt when facing this situation. Without explicit knowledge about other cultures, communicators are prone to misinterpret the intentions of the interlocutors with different cultural backgrounds. Knowledge about diversity in sociolinguistic behaviors helps learners to regard the differences as differences, not as inferiority. A lack of understanding of sociolinguistic diversity in other cultures can lead to serious cross-cultural misunderstanding.

\subsection{Recommendations for future research}

Focusing on the study of refusals of requests, the present study is explicitly restricted in scope. There remain many interesting aspects which merit further research, including:

- Investigation of the effects of non-verbal communication in cross-cultural refusals.

- Study of teaching materials for stimulating students' interest in cross-cultural communication.

- A study done for all universities in Turkey to have a more comprehensive result and to make more effective suggestions.

- Another study in the same field comparing government universities and private universities.

\subsection{Usability of study results \\ 6.2.1 Implications}

According to Raines (1999), "language is the most typical, the most representative and the most central element in any culture. Language and culture are simply not separable; one cannot fully understand the nature of either language or culture unless they are seen as inseparable. It follows that second language learning is often second culture learning" (Brown 1989).(As cited in Nguyen, 2006:71)

The results of the present study demonstrate that refusing in an L2 is a complex task because it requires the acquisition of the socio-cultural values of the target culture. In order to effectively communicate in the L2, the learner needs to acquire the socio-cultural strategies used most frequently by native speakers, and the rules for their appropriate implementation. We can, therefore, make the following pedagogical recommendations for L2 instruction:

- To develop pragmatic ability in the FL classroom, language instructors should design contextualized, task-based activities which expose learners to different types of pragmatic input and prompt learners to produce appropriate output;

- To successfully perform a speech act, language instructors should teach language forms and functions contextually in communicative oral activities in both formal and informal situations in order to develop the learners' sociolinguistic ability in an L2.

- Both socio-cultural and sociolinguistic information should be incorporated into the language curriculum and language textbooks. Specifically, students should be taught how to perform different speech acts in an L2 in different situations of social status, social distance, and with reference to the gender relation between the speakers and interlocutors.

FitzGerald (1999) argues that we as teachers should not forget that we are preparing our students not only for the domestic workplace and society. Our world is shrinking and the possibility of our students working abroad, or even at home with foreigners is much greater than 

refusals ofrequests.Journal of Human Sciences, 14(2), 1517-1533. doi:10.14687/jhs.v14i2.4575

before. Our students are very likely to need to communicate with both native and non-native speakers of English.

\subsubsection{Implications on ELT}

The sole aim of language learners is to express their thoughts and feelings via foreign language. Nevertheless, in this context, it is a widely known fact that most learners are fraught with difficulties in learning a foreign language. The basic principles of pragmatic approach form the basis in reaching communicative success. Language users cannot reach competency in expressiveness without pragmatic adequacy. Inadequacy of this kind causes serious problems in use. In this sense, foreign language classroom must be the most suitable context where the most sufficient information is given to students. However, it is also a widely known fact that students who learn a language outside this target language community come across with the problem of alienation from the aspect of competence in cross-cultural gists. In order to overcome this problem some alterations in syllabus can be made. The syllabus must cover sociolinguistic features which constitute a pragmatic perspective. The borders of syllabus design must have adequacy and flexibility.

It is hoped that the results of this study lead to more awareness of the similarities and differences between the use of speech acts with regard to the performance of refusals as one of the face-threatening speech acts and pragmatic competence of the Turkish non-native speakers of English. As no other study on the use of speech set of English refusals from the aspect of Turkish EFL teacher trainees has been reported so far, there was no evidence for the results of the present study in literature.

Another difference across language groups was the context variable, which needs to be highlighted for the sake of ELT. The two groups didn't show much difference in a formal setting; that is both of the groups preferred similar strategies in refusing to a professor. However, when communicating to a friend at the same age, TEFL group preferred similar strategies to the professor situation which is the proof of being unable to differentiate the suitable way of choosing the correct use in the suitable context. The fact that the students are exposed to overuse of grammatical structures in classroom setting and they lacked direct exposure to the target culture causes this fact. Lyuh contends that (1992:119) awareness of the diversity of social behaviors makes it possible to perceive the differences as differences, not as inferiority or abnormality. So as to do that explicit knowledge or direct exposure to other culture is necessary. It is believed that learning about differences can reduce unnecessary hostility toward other groups due to the lack of understandings of other cultures. In order to be pragmatically competent in the target language, the importance of the sociolinguistic rules of language use has been recognized by many researchers (Bardovi- Harlig, 1992; Einsestein and Bodma, 1986; Bouton, 1994; Cohen, 1996) and deviations such as the ones presented in this study may lead to misunderstandings and communication breakdown. (As cited in Nguyen, 2006)

\section{References}

Akınc1-Akkurt, P. (2007). A Case Study On Assessing Pragmatic Awareness of Turkish EFL Learners Via Speech Act Set Of Complaints: A Cross- Cultural Pragmatic Perspective. Unpublished Master's Thesis. GaziUniversity, Ankara.

Alptekin, C. (2002). Toward intercultural communicative competence in ELT.Engslish Language Teaching Journal, 56(1), 57-64.

Banerjee, J., \& Carrell, P. (1988). Tuck in your shirt, you squid: Suggestions in ESL. Language learning, 38, 313-347.

Beckers, A. M. (1999). How to say "no" without saying "no": A study of the refusal strategies of Americans and Germans. (PhD Thesis, University of Mississipi). New York: Plenum Press. 
Hergüner, S., \& Çakır, A., (2017). Determining the level of pragmatic awareness of ELT teacher trainees: A study of refusals ofrequests.Journal of Human Sciences, 14(2), 1517-1533. doi:10.14687/jhs.v14i2.4575

Beebe, L. M., \& Takahashi, T. (1989). Sociolinguistic variation in face-threatening speech acts: Chastisement and disagreement. In M.R.Eisenstein (Ed.), The dynamic interlanguage: Empirical studies in second language variation (pp. 199-218). London : Plenum Press.

Beebe, L., Takahash, T., AndUliss-Weltz R. (1990). Pragmatic transfer in ESL refusals. In Developing communicative competence in a second language R. Scarcella, E. Andersen, and S. Krashen (Editors), (p. 55-73). New York: Newbury House.

Blum-Kulka, S., \& Olshtain, E. (1984). Requests and apologies: A cross-cultural study of speech act realization patterns (CCSARP). Applied Linguistics, 5 (3), 196-212.

Blum-Kulka, S., \& Olshtain, E. (1986). Too many words: Length of utterance and pragmatic failure. Studies in Second Language Acquisitions, 8, 47-61.

Bulut, D. (2000). A Cross-cultural study of refusals in American English and Turkish. Unpublished $\mathrm{PhD}$ Thesis, Hacettepe University.

Chen, H. J. (1996). Cross-cultural comparison of English and Chinese metapragmatics in refusals, PhD Thesis, Indiana USA.

Cohen, A. D. (1996). "Speech acts".Sociolinguistics and Language Teaching. New York: Cambridge University Press.

Çakır, C. (2006). Developing Cultural Awareness In Foreign Language Teaching, Turkish Online Journal of Distance Education-TOJDE, 7, ISSN 1302- 6488. Retrieved December 02, 2006.retrieved from http://tojde.anadolu.edu.tr/tojde23/pdf/article 12.pdf

Çapar, M. (2014). How do Turkish EFL Learners say 'no'?. International Journal of Language Academy. 2 (3), 262-282.

Çiftçi, H. (2016) Refusal strategies in Turkish and English: a cross-cultural study. International Association of Research. 5 (1), 2-29.

Demir, S. (2003). Bidirectional pragmatic transfer: An investigation on refusal strategies of Turkish users of English. Unpublished Master's Thesis, Middle EastTechnical University.

Ekmekçi, E. (2015). Native and Non-Native English Instructors' Production of Refusals and Complaints: A Preliminary Case Study in a State University in Turkey. The Journal of international social research, 8 (39) 8, 613-621.

Fitzgerald, H. (1999). Adult ESL: What culture do we teach? In Striving for the third place: Intercultural competence through language education LoBianco, J., Liddicoat, A.J. and Crozet, C. (Editors), (p.127-142). Melbourne:Language Australia.

Han, T \& Burgucu-Tazegül, A. (2016). Realization of Speech Acts of Refusals and Pragmatic Competence by Turkish EFL Learners. The Reading Matrix: An International Online Journal 16 (1), 161-178.

Ikoma, T., \& Shimaru, A. (1994). Pragmatics transfer in the speech act of refusal in Japanese as a second language. Journal of Asian Pacific Communication, 5 (1), 105-129.

Lyuh, I. (1992). The art of refusal: Comparison of Korean and American cultures. PhD Thesis.Indiana University, Bloomington.

Murphy, B., \& Neu, J. (1996). My grade's too low: The speech act set of complaining. In Speech acts across cultures: Challenges to communication in a second language Gass, S. M. and New, J. (Editors.), (p. 191-216). New York: Mouton de Gruyter.

Nguyen, T. M. P. (2006). Cross-cultural Pragmatics: Refusals of Requests by Australian Native Speakers of English and Vietnamese Learners of English. (MS. Thesis) The University of Queensland.

Olshtain, E. and Weinbach, L. (1993). Interlanguage features of the speech act of complaining. In G. Kasper \& S. Blum-Kulka (Eds.), Interlanguage pragmatics (pp. 108-122). New York: Oxford University Press.

Raines, C. M. (1999). Designing curriculum to teach American culture in the ESL classroom. PhD. diss., The University of Mississippi. 
Samovar, L. A. and Porter, R. E. (2001).Communication between cultures (4th ed.). Belmont and CA: Thomson Wadsworth. speech acts: Chastisement and disagreement. In The dynamic interlanguage: Empirical studies in second language variation M.R. Eisenstein (Ed.), (p. 199-218). London : Plenum Press.

Tekylldiz, Ö. (2006). A Comparative Study on the Use of Refusals by Learners of English and Native Speakers of English in Urban and Rural Areas. Unpublished Master's Thesis.Uludağ University.

Trosborg, A. (1995). Interlanguage Pragmatics: Requests, Complaints and Apologies. Berlin, New York: Mouton Gruyter.

Wolfson, N., Marmor, T., and Jones, S. (1989). Problems in the comparison of speech act across cultures. In Cross- cultural pragmatics: Requests and apologies Blum-Kulka, S. and House, J. and Kasper G. (Ed.), (p.174-196). Norwood: Ablex. 